\title{
The discovery of dabigatran etexilate
}

\author{
Joanne van Ryn ${ }^{1 *}$, Ashley Goss ${ }^{2}$, Norbert Hauel ${ }^{3}$, Wolfgang Wienen ${ }^{4}$, Henning Priepke $^{3}$, Herbert Nar ${ }^{5}$ and \\ Andreas Clemens ${ }^{6}$ \\ ${ }^{1}$ Department of CardioMetabolic Disease Research, Boehringer Ingelheim Pharma GmbH \& Co. KG, Biberach an der Riss, Baden-Württemberg, Germany \\ ${ }^{2}$ Department of CardioMetabolic Disease Research, Boehringer Ingelheim Pharmaceuticals Inc., Ridgefield, CT, USA \\ ${ }^{3}$ Department of Medicinal Chemistry, Boehringer Ingelheim Pharma GmbH \& Co. KG, Biberach an der Riss, Baden-Württemberg, Germany \\ ${ }^{4}$ Department of Respiratory Diseases Research, Boehringer Ingelheim Pharma GmbH \& Co. KG, Biberach an der Riss, Baden-Württemberg, Germany \\ ${ }^{5}$ Department of Lead Identification and Optimization Support, Boehringer Ingelheim Pharma GmbH \& Co. KG, Biberach an der Riss, Baden-Württemberg, Germany \\ ${ }^{6}$ Global Clinical Development and Medical Affairs, Boehringer Ingelheim Pharma GmbH \& Co. KG, Ingelheim, Baden-Württemberg, Germany
}

\section{Edited by:}

Eliot Ohlstein, Drexel Med School, USA

\section{Reviewed by:}

Sanjoy Ghosh, University of British

Columbia, Canada

Juan Badimon, The Mount Sinai

School of Medicine, USA

*Correspondence:

Joanne van Ryn, Department of CardioMetabolic Disease Research, Boehringer Ingelheim Pharma $\mathrm{GmbH}$ \& Co. KG, Birkendorfer Straße 65, 88397 Biberach an der Riss, Baden-Württemberg, Germany.

e-mail: joanne.vanryn@

boehringer-ingelheim.com
Thromboembolic disease is a major cause of mortality and morbidity in the developed world and is caused by an excessive stimulation of coagulation. Thrombin is a key serine protease in the coagulation cascade and numerous efforts have been made to develop safe and effective orally active direct thrombin inhibitors (DTIs). Current anticoagulant therapy includes the use of indirect thrombin inhibitors (e.g., heparins, low-molecular-weight-heparins) and vitamin $\mathrm{K}$ antagonists such as warfarin. However there are several caveats in the clinical use of these agents including narrow therapeutic window, parenteral delivery, and foodand drug-drug interactions. Dabigatran is a synthetic, reversible DTI with high affinity and specificity for its target binding both free and clot-bound thrombin, and offers a favorable pharmacokinetic profile. Large randomized clinical trials have demonstrated that dabigatran provides comparable or superior thromboprophylaxis in multiple thromboembolic disease indications compared to standard of care. This minireview will highlight the discovery and development of dabigatran, the first in a class of new oral anticoagulant agents to be licensed worldwide for the prevention of thromboembolism in the setting of orthopedic surgery and stroke prevent in atrial fibrillation.

Keywords: dabigatran, thrombin, oral anticoagulant, warfarin, stroke, atrial fibrillation, venous thromboembolism

\section{INTRODUCTION}

Thrombin is a serine protease and is the main effector protease in the blood coagulation cascade (Figure 1A), exhibiting both pro- and anticoagulant properties (Griffin, 1995; Di Cera, 2008). Thrombin (FIIa) is generated via proteolytic cleavage from inactive prothrombin (FII) by factor $\mathrm{Xa}$ (FXa) in the prothrombinase complex, which assembles when circulating coagulation factors come into contact with tissue factor (TF) on exposed extravascular tissues. Thrombin plays a central role in the initiation and propagation of thrombotic disease by activating platelets, catalyzing fibrinogen conversion into fibrin, and promoting clot stabilization (Lane et al., 2005). Thrombin activates upstream factors in the cascade to amplify the coagulation response and enhance thrombin generation. Its activity is inhibited via endogenous circulating anticoagulants including antithrombin (AT), heparin cofactor II (HCII), and binding to the cofactor thrombomodulin (TM) to activate the anticoagulant protein C (Griffin, 1995). Thrombin also induces many cellular effects via a family of G-protein coupled protease activated receptors (PAR), PAR1, PAR3, and PAR4 (Coughlin, 2005; Figure 1B). The expression of PAR1 on the endothelium and vasculature, in both physiological and disease states, suggests that thrombin plays a role in these contexts.

Established anticoagulation therapy has targeted thrombin. The parenteral agents heparin and low molecular weight heparins (LMWH) catalyze the inhibition of thrombin by AT and are used for prophylaxis and treatment of venous thromboembolism (VTE) in many indications (Hirsh et al., 2008). Other approved parenteral thrombin inhibitors include the recombinant hirudin lepirudin and synthetic direct thrombin inhibitor (DTI) argatroban (Coppens et al., 2012), for predominantly heparin-induced thrombocytopenia (Yeh and Jang, 2006), and the oligopeptide bivalirudin in percutaneous coronary interventions (Warkentin et al., 2008).

As the only available oral therapy, warfarin and its derivatives have been used for over 50 years in long-term anticoagulation treatment (Hirsh et al., 1998). Warfarin, a Vitamin K antagonist (VKA), blocks the biosynthesis of thrombin and other coagulation factors and has proven effective in inhibiting thrombosis. However, administration is problematic due to its slow onset-offset of activity, and drug-drug and drug-food interactions which require frequent monitoring and dose adjustment to maintain appropriate anticoagulation (Mann, 2005).

Research activities in many pharmaceutical companies have focused on the identification of novel thrombin inhibitors. In 2004 a new DTI ximelagatran (AstraZeneca; Gustafsson et al., 2004) gained approval in several countries for short-term anticoagulation treatment after orthopedic surgery, but was later withdrawn due to hepatotoxicity reports. Other companies concentrated their research activities on discovering FXa inhibitors (Pinto et al., 2010) including two recently approved FXa inhibitors - rivaroxaban and apixaban for treatment and prevention of VTE after orthopedic surgery (Pinto et al., 2007; Perzborn et al., 2011) and stroke prevention in atrial fibrillation (Granger et al., 2011; Patel et al., 2011). 
A Thrombin in the Coagulation Cascade

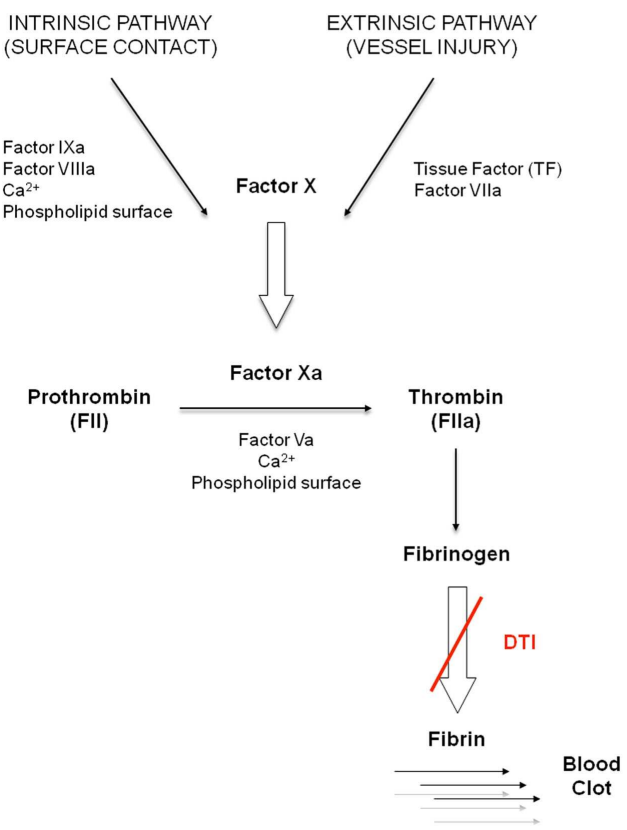

B

Pleiotropic Effects of Thrombin Signaling

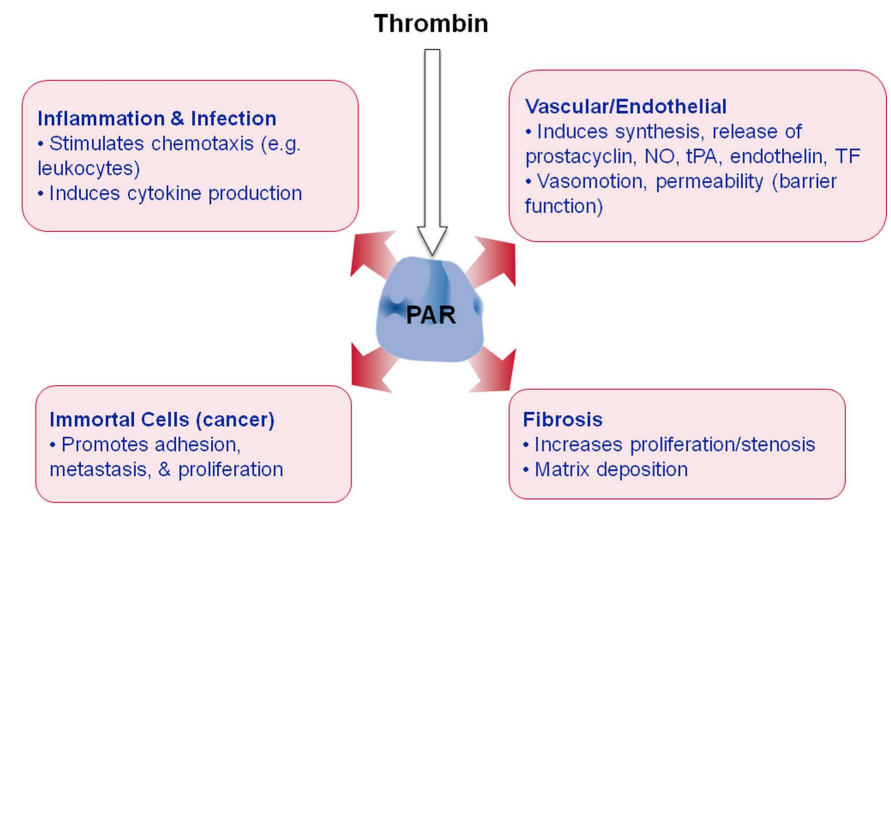

FIGURE 1 | (A) Simplified schematic of thrombin in the coagulation cascade.

. (B) Overview of thrombin's non-hemostatic effects via PAR receptor signaling in diverse cell types.

Two additional FXa inhibitors, edoxaban (Furugohri et al., 2008) and betrixaban (Zhang et al., 2009), are completing Phase III trials.

This review will focus on the development of dabigatran (Hauel et al., 2002), the first new oral anticoagulant (NOAC) to gain market approval for long-term indications 50 years after introduction of warfarin. Dabigatran is approved in over 70 countries, including the U.S., Canada, Europe, and Japan, for stroke prevention in patients with atrial fibrillation and for the prevention of thrombosis after orthopedic hip and knee surgery. Dabigatran is a potent, reversible, and direct inhibitor of thrombin, with a good efficacy, safety, and tolerability profile as compared to both warfarin and LMWH (Hankey and Eikelboom, 2011).

\section{DABIGATRAN DISCOVERY AND PRECLINICAL PHARMACOLOGY}

Twenty years ago an X-ray crystal structure of a bovine thrombin complex formed with the peptide-like benzamidine based inhibitor NAPAP revealed the conformation of an enzyme-bound thrombin inhibitor and its interactions with the residues of the active site cleft (Brandstetter et al., 1992). This data spurred the design of a new class of inhibitor molecules with increased inhibitory potency toward human $\alpha$-thrombin and acceptable metabolic stability and pharmacokinetic properties (Davis and Teague, 1999; Hauel et al., 2002).

A lead compound (dabigatran; Figure 2A) was identified because of its favorable selectivity profile and strong in vitro and in vivo activity, exhibiting long anticoagulation duration in rats after i.v. administration and toleration at high doses (Wienen et al., 2007a). However it was not orally active due to its polarity and the compound was converted into an orally active prodrug (dabigatran etexilate; Himmelsbach et al., 1995). Given orally to rhesus monkeys, this prodrug exhibited strong and long lasting anticoagulant effects as measured by the activated partial thromboplastin time (aPTT) exvivo (Wienen et al., 2007a). Based on its promising profile, dabigatran etexilate was selected for clinical development.

\section{MOLECULAR MECHANISM OF ACTION OF DABIGATRAN}

Dabigatran inhibits human thrombin in a concentrationdependent and competitive fashion, with a $K_{i}$ of $4.5 \mathrm{nM}$. This inhibition is rapid and reversible, and comparison to $\mathrm{IC}_{50}$ values for other coagulation proteases demonstrated its high selectivity for thrombin (Wienen et al., 2007a). Dabigatran inhibits both clot-bound and free thrombin, and this binding is independent of whether thrombin is bound via the exosite to fibrin or is present as free enzyme in plasma (van Ryn et al., 2008).

Thrombin generated on the platelet surface is a potent agonist mediating platelet activation. Dabigatran inhibits thrombininduced platelet aggregation, but has no inhibitory effect on platelet aggregation induced by arachidonic acid, collagen, or ADP (Wienen et al., 2007a). Dabigatran also effectively inhibits TF-induced thrombin generation in human platelet poor plasma (PPP) in a concentration-dependent manner.

\section{IN VITRO ANTIHEMOSTATIC EFFECTS OF DABIGATRAN}

Consistent and potent in vitro anticoagulant activity of dabigatran has been demonstrated using clotting assays across several species 
A

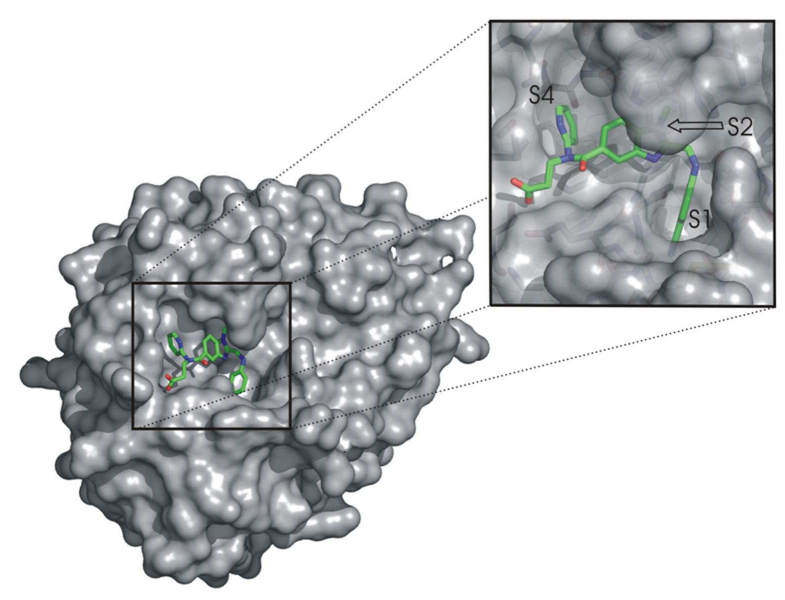

B

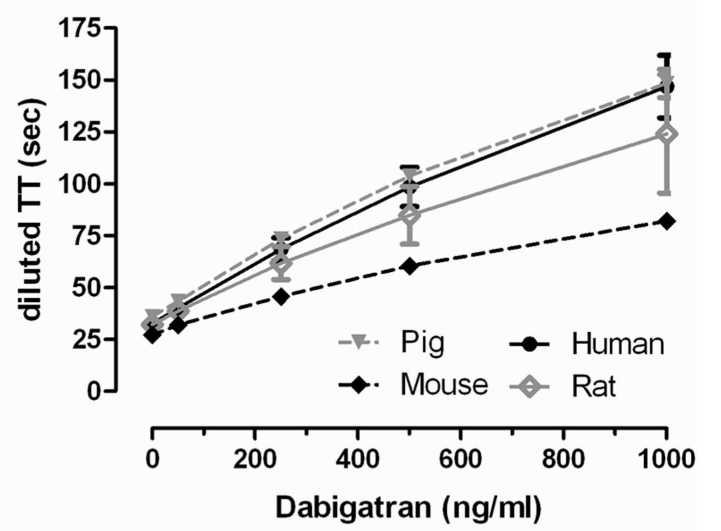

\begin{tabular}{|c|c|c|c|c|}
\hline $\mathbf{n g} / \mathbf{m l}$ & Human & Pig & Rat & Mouse \\
\hline $\mathrm{EC}(\mathrm{T} 2)$ & 213 & 232 & 261 & 380 \\
\hline $\mathrm{EC}(\mathrm{T} 3)$ & 490 & 549 & 639 & 1005 \\
\hline
\end{tabular}

FIGURE 2 | (A) Surface representation of Flla bound to dabigatran. The insert shows a zoom into the active site cleft of the enzyme. The most prominent feature of the ligand-protein interaction interface is the deep S1 pocket in which the benzamidine moiety binds. The 60-loop insertion of Flla with the prominent Trp-60D occludes a hydrophobic S2 pocket in which the methylbenzimidazole of dabigatran nicely fits. The $\mathrm{S} 4$ pocket is rather shallow pocket that prefers to bind aromatic moieties of inhibitors. Dabigatran occupies the S4 pocket with its pyridyl ring that forms an edge-on $\mathrm{CH}$... $\pi$ interaction with Trp-215 at the floor of the pocket and places its propionic acid group into the solvent exposed S3 pocket. (B) Effect of increasing concentrations of dabigatran on diluted thrombin time measurements in different species. The EC(T2) and EC(T3) represent the effective concentration of dabigatran to prolong the clotting time either twofold or threefold. Data represented as mean \pm SE, $n=4-5$.
(Wienen et al., 2007a). A doubling of the aPTT, prothrombin time (PT), and ecarin clotting time (ECT) is observed at dabigatran concentrations ranging from 0.1 up to $4.6 \mu \mathrm{M}$, with the ECT being the most sensitive parameter for anticoagulant activity. The thrombin time (TT) assay is extremely sensitive to dabigatran's effects and the commercially available Hemoclot ${ }^{\circledR}$ Thrombin Inhibitor assay (Hyphen BioMed, Neuville-sur-Oise, France) is a diluted thrombin time (dTT) assay sensitive enough for accurate quantitative measurement of dabigatran activity across a broad concentration range (van Ryn et al., 2010). Thrombin inhibition by dabigatran was comparable in pig and human plasma, and inhibition of rat thrombin was $\sim 20 \%$ less potent than human, and mouse thrombin $\sim$ twofold less potent than human (Figure 2B).

\section{EX VIVO ANTIHEMOSTATIC EFFECTS OF DABIGATRAN}

Significant dose- and time-dependent anticoagulant efficacy ex vivo has been demonstrated after i.v. administration of dabigatran to rats and rhesus monkeys. In rats, doses of $0.3,1$, and $3 \mathrm{mg} / \mathrm{kg}$ i.v. produce a maximum prolongation of the ex vivo aPTT to 29,159 , and $582 \mathrm{~s}$, respectively, $5 \mathrm{~min}$ after administration. In rhesus monkeys, i.v. administration $(0.15,0.3$, or $0.6 \mathrm{mg} / \mathrm{kg})$ of dabigatran prolongs the aPTT to $47.3,70.1$, and $98.9 \mathrm{~s}$, respectively, $5 \mathrm{~min}$ after administration and this is sustained beyond $8 \mathrm{~h}$. Notably, single oral doses of $1,2.5$, and $5 \mathrm{mg} / \mathrm{kg}$ administered to conscious rhesus monkeys all revealed a significant and long lasting $(>8 \mathrm{~h}$ ) prolongation of the aPTT (Hauel et al., 2002; Wienen et al., 2007a).

\section{VENOUS AND ARTERIAL ANTITHROMBOTIC EFFECTS OF DABIGATRAN}

Infusion of dabigatran in a rat model of induced venous thrombosis inhibited clot formation dose-dependently and completely (Wienen et al., 2007b). No significant increase in bleeding time was observed at the maximum effective antithrombotic dose. In the same model, dabigatran etexilate administered orally between 0.5 and $7 \mathrm{~h}$ prior to thrombus induction resulted in a dose and timedependent inhibition of thrombus formation. In a rabbit arteriovenous shunt model of thrombosis, infusion and oral administration of dabigatran revealed a dose-dependent inhibition of clot formation (Wienen et al., 2007c). In both the rat and rabbit thrombosis models the observed antithrombotic effects were inversely correlated with a dose and time-dependent prolongation of the ex vivo aPTT.

In the Folts model of arterial thrombosis in pigs, aspirin (ASA) treatment reduced cyclic flow reductions by $40 \%$ and dabigatran reduced by $44 \%$. Given together, the two compounds reduced closures by $88 \%$ and proved to be safe and effective in this model. Additionally, a complete closure of the injured vessels was not observed at clinically relevant plasma levels in the dabigatrantreated and the dabigatran-ASA treated animals, demonstrating effectiveness in an arterial thrombosis setting (van Ryn et al., 2009).

\section{PLEIOTROPIC EFFECTS OF THROMBIN - PRECLINICAL OBSERVATIONS}

In addition to its role in hemostasis, thrombin directly and indirectly affects cell behavior and responses in a variety of tissue types via PAR receptor signaling, and has been implicated in a variety of 
diseases (Coughlin, 2005), suggesting other potential indications where thrombin inhibition could be beneficial. These therapeutic areas include diseases underscored by inflammation (van der Poll et al., 2011), infection (Levi et al., 2012), fibrosis (Chambers and Laurent, 2002), and cancer (Palumbo and Degen, 2000), among others. To date, many disease areas where thrombin-PAR signaling has been implicated are being investigated preclinically for beneficial effects of direct thrombin inhibition by dabigatran and several are described below. However effects in the clinic are unknown.

\section{ATHEROSCLEROSIS}

There is increasing evidence in experimental atherosclerosis that inflammation and coagulation play an important role in atherosclerotic development (Borissoff et al., 2009, 2011). In separate studies utilizing the Apo $\mathrm{E}^{-1-}$ mouse model of atherosclerosis, mice were fed high fat control diet or diet supplemented with dabigatran for up to 20 weeks. In all studies, dabigatranfed mice exhibited reduced atherosclerotic lesion size along with enhanced plaque stability, improved endothelial function, and reduced oxidative stress (Preusch et al., 2010; Kadoglou et al., 2012; Lee et al., 2012). Another study in a procoagulant/atherosclerotic mouse model ( $\mathrm{ApoE}^{-1-}: \mathrm{TM}^{\text {pro/pro }}$ ) having elevated coagulation activity due to a loss-of-function mutation in TM demonstrated that dabigatran significantly reduced plaque area and stenosis after a carotid cuff injury (Borissoff et al., 2010).

\section{CANCER}

A link between cancer and thrombosis has long been recognized (Iodice et al., 2008) and there is experimental evidence implicating PAR1-mediated events and expression with tumor growth and metastasis (Booden et al., 2004). Studies testing the effects of dabigatran treatment (4 weeks) in a syngeneic mouse model of breast cancer demonstrated a reduction in both primary tumor growth and metastasis in dabigatran-treated mice as compared to control (DeFeo et al., 2010).

\section{FIBROSIS}

One hallmark of atrial fibrillation and many other degenerative diseases (e.g., renal disease, idiopathic pulmonary fibrosis) is the extent of fibrosis (Tan and Zimetbaum, 2011). Activation of coagulation following tissue injury is an early fibrotic response leading to the deposition of fibrin. Notably, thrombin activation of PAR1 can differentiate normal lung fibroblasts into a myofibroblast phenotype, inducing fibrogenic cytokine release and increased expression of extracellular matrix proteins (Bogatkevich and Silver, 2009). These effects are inhibited in vitro by dabigatran, and in bleomycin-induced pulmonary injury in mice chronic dabigatran etexilate treatment reduced the extent of fibrosis and collagen release (Bogatkevich et al., 2011).

\section{INFECTIONS WITH STAPHYLOCOCCUS AUREUS}

The potential of $S$. aureus to coagulate blood is used as a diagnostic feature of the pathogen and more recently it has been shown that $S$. aureus achieves this by secreting a procoagulant, called coagulase (McAdow et al., 2011). Coagulase directly converts prothrombin into thrombin, bypassing upstream coagulation and allows S. aureus to envelope itself in protective fibrin strands, which may aid in its resilience to antibiotics (Vanassche et al., 2011). Dabigatran directly inhibits coagulase, unlike heparin and hirudin, and thus prevents fibrin formation and may increase the sensitivity of S. aureus to antibiotics (Vanassche et al., 2010, 2011, 2012).

\section{CLINICAL STUDIES AND INDICATIONS}

For 50 years VKAs have been the standard in chronic anticoagulation treatment, however their many associated drawbacks has led to significant clinical underuse in atrial fibrillation patients. There is a significant unmet medical need to develop anticoagulation treatment that is easy to use, predictable, effective, and safe. Dabigatran etexilate represents the first broadly approved NOAC with these attributes.

Dabigatran has a fast onset of action (peak plasma concentrations $2-3 \mathrm{~h}$ after ingestion) with a half-life of $12-14 \mathrm{~h}$ (Stangier and Clemens, 2009). It does not require routine coagulation monitoring, has no drug-food interactions, is not metabolized by cytochrome P 450 enzymes, and does not require dose adjustment for moderate liver disease (Garnock-Jones, 2011). As a substrate for the Pgp transporter there is the potential for drug interactions with agents using this transporter (e.g., verapamil, amiodarone, rifampicin), which may necessitate dose adaptation (Huisman et al., 2012; Härtter et al., 2012). Dabigatran is $80 \%$ renally excreted, thus prior to commencing dabigatran treatment renal function should be assessed, and in the instance of emergency situations dabigatran is dialyzable due to low protein binding ( 30\%; Huisman et al., 2012). As with all anticoagulants, dabigatran's most common side effect is bleeding. In RE-LY, there was a significantly higher risk of gastrointestinal bleeding with dabigatran $150 \mathrm{mg}$ bid compared with warfarin (Connolly et al., 2009). No statistical significant difference was seen when using the $110 \mathrm{mg}$ BID dabigatran dose. Mild to moderate dyspepsia related to dabigatran was also reported. The side effect tended to be transient, and may be managed by giving dabigatran with a large glass of water, with food, or a proton-pump inhibitor (PPI; Bytzer et al., 2012; Hoffman and Galle, 2013).

\section{PREVENTION OF DEEP VENOUS THROMBOSIS}

Dabigatran has been studied in more than 10,000 patients in four phase III trials of deep venous thrombosis (DVT) and pulmonary embolism (PE) prophylaxis in major orthopedic surgery and demonstrated a good overall safety profile in this setting (Fuji et al., 2010; Dahl et al., 2012; Eriksson et al., 2012a,b). In total knee replacement (TKR), when compared to enoxaparin $30 \mathrm{mg}$ twice daily (BID), dabigatran etexilate at 150 and $220 \mathrm{mg}$ once daily (OAD) was inferior due to a greater number of distal thromboses (Ginsberg et al., 2009). In studies comparing dabigatran to $40 \mathrm{mg}$ of enoxaparin, equivalence was shown for both thrombosis prevention and bleeding in total hip replacement (THR) and TKR (Eriksson et al., 2007a,b). The THR results were reproduced in the RE-NOVATE II trial and dabigatran additionally demonstrated superior reduction of major VTE (including DVT and PE) with a same rate of major bleeding (Eriksson et al., 2011a). A pooled analysis of the THR trials demonstrated its superiority in the prevention of major VTE (Friedman et al., 2010; Eriksson et al., $2011 b)$. In the countries where dabigatran etexilate is approved for 
VTE prophylaxis it is recommended at a dose of 220 or $150 \mathrm{mg}$ OAD for patients with renal impairment or taking a Pgp inhibitor.

\section{THERAPY OF VENOUS THROMBOEMBOLISM}

In the treatment of VTE $150 \mathrm{mg}$ BID dabigatran etexilate was compared to standard warfarin treatment (Schulman et al., 2009). In the acute treatment setting, all patients received heparin or LMWH for a median of 9 days prior to treatment with an oral anticoagulant. Dabigatran demonstrated the same efficacy in thrombosis prevention with significantly less minor bleeding and similar major bleeding. The extension studies RE-MEDY (vs. warfarin) and RE-SONATE (vs. placebo) showed similar efficacy and improved bleeding profile compared to warfarin, and a 92\% relative risk reduction of recurrent VTE with elevated clinically relevant non-major bleeding but no statistical difference in major bleeding compared to placebo (Schulman et al., 2011a,b). The RE-SONATE study showed for the first time significant efficacy of an oral anticoagulant in the prevention of thromboembolic events with a good safety profile. Acute treatment and secondary prevention of VTE have not yet been registered.

\section{STROKE PREVENTION IN PATIENTS WITH ATRIAL FIBRILLATION}

In the RE-LY study, 18,113 patients with atrial fibrillation (AF) and at least one risk factor for stroke were randomized between warfarin, 110 or $150 \mathrm{mg}$ BID dabigatran etexilate (Connolly et al., 2009). The RE-LY trial was the only phase III study in the field of NOACs carrying enough power to evaluate two different doses and define the most appropriate patient population for a specific dose. The $150 \mathrm{mg}$ BID dose showed superior efficacy in stroke prevention and systemic embolism with similar major bleeding rate compared to well controlled warfarin. The $110 \mathrm{mg}$ BID dose had a significantly lower major bleeding rate and the same efficacy as warfarin. Both doses showed a significant (up to 70\%) reduction of intracranial hemorrhage and a reduction in lifethreatening bleeding. There was a non-significant $12 \%$ mortality benefit $(p=0.051$ ) with the $150 \mathrm{mg}$ BID dose (Connolly et al., 2010).

These results were consistent across all patient groups, including those with a prior history of stroke or transient ischemic attack (Diener et al., 2010), patients previously on warfarin, or those new to oral anticoagulation (Ezekowitz et al., 2010). Interestingly the effects seen under both doses were independent from gender, weight, ethnicity, renal impairment grade, $\mathrm{CHADS}_{2}$ scores, concomitant diseases (e.g., hypertension, diabetes, heart failure), and treatments (Connolly et al., 2009, 2010; Eikelboom et al., 2011). A RE-LY subgroup analysis has indicated an interaction between age and bleeding endpoints, with dabigatran $150 \mathrm{mg}$ BID efficacy persisting for all age groups while dabigatran $110 \mathrm{mg}$ BID in patients above 80 years improves safety profile (Eikelboom et al., 2011).

For stroke prevention, the FDA recommends a lower therapeutic dose (75 mg BID) in patients with severe renal impairment [creatinine clearance $(\mathrm{CrCl}) 15-30 \mathrm{ml} / \mathrm{min}$ ] and no use in patients with $\mathrm{CrCl}$ under $15 \mathrm{ml} / \mathrm{min}$. In Europe two doses $(150,110 \mathrm{mg}$ BID) exist which enables tailored dosing and is contraindicated in patients with a $\mathrm{CrCl}$ below $30 \mathrm{ml} / \mathrm{min}$.

\section{PREVENTION OF RECURRENT MYOCARDIAL INFARCTION IN PATIENTS WITH ACUTE CORONARY SYNDROME}

In the RE-DEEM phase II dose identification study, dabigatran plus dual antiplatelet therapy showed an expected dose-dependent increase in bleeding and significantly reduced coagulation activity (Oldgren et al., 2011). In the 150 and $110 \mathrm{mg}$ BID dose groups, the composite of cardiovascular death, non-fatal myocardial infarction or hemorrhagic stroke or cardiovascular death or all-cause death alone were numerically lower compared to placebo (dual antiplatelet therapy). The safety profile in this post-ACS population was acceptable and a RE-LY subanalysis study found that concomitant use of antiplatelets led to an expected doubling of bleeding rates in both dabigatran and warfarin treatment groups (Connolly et al., 2009).

\section{MECHANICAL HEART VALVES}

Thromboprophylaxis after mechanical heart valve implantation is required for the lifetime of the patient, thus the concept of a DTI as a potential therapy was tested preclinically. In vitro, human blood anticoagulated with dabigatran circulating over a mechanical heart valve in a closed circuit effectively prevented fibrin deposition and thrombus formation compared to control (Maegdefessel et al., 2010). In an experimental swine model with a heart valve grafted onto the descending aorta, dabigatran administered post implantation for 30 days vs. LMWH significantly reduced valve thrombus and platelet deposition (McKellar et al., 2011). In a separate study, swine underwent mitral valve replacement and received dabigatran or warfarin for 90 days (Schomburg et al., 2012). Valve thrombus was observed in all groups; however there was decreased incidence of bleeding and a significant mortality benefit in the dabigatran-treated group vs. warfarin. Dabigatran's effects in the setting of mechanical valve replacement was investigated in the dose-finding RE-ALIGN phase II study (Van de Werf et al., 2012), however the study was discontinued because interim analysis showed an increased incidence of thromboembolic events compared to warfarin. Therefore dabigatran is contraindicated in patients with mechanical prosthetic valves (FDA Drug Safety Communication, 2012).

\section{SUMMARY}

Based on a NAPAP-thrombin X-ray crystal structure a new class of thrombin inhibitors was designed, with the potency of these compounds optimized over several iterative steps. One inhibitor, dabigatran, demonstrated very strong in vivo activity, however due to its highly polar nature, oral absorption was insufficient. Several prodrugs were synthesized from which dabigatran etexilate emerged as a strong clinical candidate.

Preclinical pharmacological investigations illustrated that dabigatran is an effective antithrombotic agent in both venous and arterial models. In an unprecedented clinical trial program that included $\sim 38,000$ patients, dabigatran was shown to be a highly effective anticoagulant with a good safety profile. Dabigatran is as effective as enoxaparin in the prevention of venous thrombosis after orthopedic surgery, and as effective as warfarin in the therapy of acute thrombosis or secondary prevention of VTE with no increased risk of bleeding. In stroke prevention in atrial fibrillation, it was more effective than well controlled warfarin with 
remarkable decreased risk of intracranial hemorrhage. Furthermore, since thrombin has been shown to play a central role in many disease processes, dabigatran is being investigated in additional biochemical pathways for potential beneficial effects in preclinical translational and disease models.

\section{REFERENCES}

Bogatkevich, G. S., Ludwicka-Bradley, A., Nietert, P. J., van Ryn, J., and Silver, R. M. (2011). Antifibrotic effects of the oral, direct thrombin inhibitor dabigatran etexilate on lung injury in mice model of pulmonary fibrosis. Arthritis. Rheum. 63, 1416-1425.

Bogatkevich, G. S., and Silver, R. (2009). Dabigatran inhibits the thrombin-induced differentiation of lung fibroblasts to a myofibroblast phenotype. Arthritis. Rheum. 60, 3455-3464.

Booden, M. A., Eckert, L. B., Der, C. J., and Trejo, J. A. (2004). Persistent signaling by dysregulated thrombin receptor trafficking promotes breast carcinoma cell invasion. Mol. Cell. Biol. 24, 1990-1999.

Borissoff, J. I., Loubele, S. T., Leenders, P., Soehnlein, O., Koenen, R. R., van Oerle, R., et al. (2010). Direct thrombin inhibition by dabigatran protects against severe atherosclerosis progression in prothrombotic mice. Circulation 122(Suppl. 1), A19384. [Abstract].

Borissoff, J. I., Spronk, H. M. H., Heeneman, S., and ten Cate, H. (2009). Is thrombin a key player in the 'coagulation atherogenesis' maze? Cardiovasc. Res. 82, 392-403.

Borissoff, J. I., Spronk, H. M. H., and ten Cate, H. (2011). The haemostatic system as a modulator of atherosclerosis. N. Engl. J. Med. 364, 1746-1760.

Brandstetter, H., Turk, D., Hoeffken, H. W., Grosse, D., Stuerzebecher, J., Martin, P. D., et al. (1992). Refined 2.3 a X-ray crystal structure of bovine thrombin complexes formed with the benzamidine and argininebased thrombin inhibitors NAPAP, 4-TAPAP and MQPA. J. Mol. Biol. 226, 1085-1099.

Bytzer, P., Connolly, S. J., Yang, S., Ezekowitz, M., Formella, S., Reilly, P. A., et al. (2012). Analysis of upper gastrointestinal adverse events among patients given dabigatran in the RE-LY trial. Clin. Gastroenterol. Hepatol. doi: 10.1016/j.cgh.2012.10.021

Chambers, R. C., and Laurent, G. J. (2002). Coagulation cascade proteases and tissue fibrosis. Biochem. Soc. Trans. 30, 194-200.

Connolly, S. J., Eszekowitz, M., Yusuf, S., Reilly, P. A., and Wallentin, L. (2010). Newly identified events in the RE-LY trial. N. Engl. J. Med. 363, 1875-1876.

Connolly, S. J., Ezekowitz, M. D., Yusuf, S., Eikelboom, J., Oldgren, J., Parekh, A., et al. (2009). Dabigatran versus warfarin in patients with atrial fibrillation. N. Engl. J. Med. 361, 1139-1151.

Coppens, M., Eikelboom, J. W., Gustafsson, D., Weitz, J. I., and Hirsch, J. (2012). Translational success stories: development of direct thrombin ini-

Coughlin, S. R. (2005). Proteasethrombosis and vascular biology. $J$. Thromb. Haemost. 3, 1800-1814.

Dahl, O. E., Kurth, A. A., Rosencher, N., Noack, H., Clemens, A., and Eriksson, B. I. (2012). Thromboprophylaxis in patients older than impairment undergoing knee or hip replacement surgery. Int. Orthop. 36, 741-748.

Davis, A. M., and Teague, S. J. (1999). Hydrogen bonding, hydrophobic interactions, and failure of the rigid receptor hypothesis. Angew. Chem. Int. Ed. 38, 736-749.

DeFeo, K., Hayes, C., Chernick, M., van Ryn, J., and Gilmour, S. K. (2010). Use of dabigatran etexilate to reduce breast cancer progression. Cancer Biol. Ther. 10, 1001-1008.

Di Cera, E. (2008). Thrombin. Mol. Aspects Med. 29, 203-254.

Diener, H. C., Connolly, S. J., Ezekowitz, M. D., Wallentin, L., Reilly, P. A., Yang, S., et al. (2010). Dabigatran compared with warfarin in patients with atrial fibrillation and previous transient ischaemic attack or stroke: a subgroup analysis of the RE-LY trial. Lancet Neurol. 9, 1157-1163.

Eikelboom, J. W., Wallentin, L., Connolly, S. J., Ezekowitz, M., Healey, J. S., Oldgren, J., et al. (2011). Risk of bleeding with 2 doses of dabigatran compared with warfarin in older and younger patients with atrial fibrillation: an analysis of the randomized evaluation of long-term anticoagulant therapy (RE-LY) trial. Circulation 123, 2363-2372.

Eriksson, B. I., Dahl, O. E., Feuring, M., Clemens, A., Noack, H., Hantel, S., et al. (2012a). Dabigatran is effective with a favourable safety profile in normal and overweight patients undergoing major hibtors. Circ. Res. 111, 920-929. activated receptors in hemostasis, 75 years or with moderate renal

More than 50 years after the introduction of warfarin, the development of dabigatran can be seen as a breakthrough achievement for the treatment of thromboembolic disease including the prevention of catastrophic strokes in patients.

orthopaedic surgery: a pooled analysis. Thromb. Res. 130, 818-820.

Eriksson, B. I., Dahl, O. E., Rosencher, N., Clemens, A., Hantel, S., and Kurth, A. A. (2012b). Efficacy of delayed thromboprophylaxis with dabigatran: pooled analysis. Thromb. Res. 130, 871-876.

Eriksson, B. I., Dahl, O. E., Huo, M. H., Kurth, A. A., Hantel, S., Hermansson, K., et al. (2011a). Oral dabigatran versus enoxaparin for thromboprophylaxis after primary total hip arthroplasty (RENOVATE II). Thromb. Haemost. 105 , 721-729.

Eriksson, B. I., Kurth, A. A., Dahl, O. E., Clemens, A., Schnee, J., Hantel, S., et al. (2011b). Oral dabigatran etexilate vs. enoxaparin for prevention of venous thromboembolism after total hip arthroplasty: a pooled analysis of two randomized trials. J. Thromb. Haemost. 9(Suppl. 2), 856-857.

Eriksson, B. I., Dahl, O. E., Rosencher, N., Kurth, A. A., van Dijk, C. N., Frostick, S. P., et al. (2007a). Oral dabigatran etexilate vs. subcutaneous enoxaparin for the prevention of venous thromboembolism after total knee replacement: the RE-MODEL randomized trial. J. Thromb. Haemost. 5, 2178-2185.

Eriksson, B. I., Dahl, O. E., Rosencher, N., Kurth, A. A., van Dijk, C. N., Frostick, S. P., et al. (2007b). Dabigatran etexilate versus enoxaparin for prevention of venous thromboembolism after total hip replacement: a randomised, double-blind, non-inferiority trial. Lancet 370 949-956.

Ezekowitz, M. D., Wallentin, L., Connolly, S. J., Parekh, A., Chernick, M. R., Pogue, J., et al. (2010). Dabigatran and warfarin in vitamin $\mathrm{K}$ antagonist-naive and -experienced cohorts with atrial fibrillation. Circulation 122, 2246-2253.

FDA Drug Safety Communication. (2012). Pradaxa (Dabigatran Etexilate Mesylate) Should Not be Used in Patients with Mechanical Prosthetic Heart Valves. Available at: http://www.fda.gov/Drugs/ DrugSafety/ucm332912.htm\#safety [December 19, 2012].

Friedman, R. J., Dahl, O. E., Rosencher, N., Caprini, J. A., Kurth, A. A., Francis, C. W., et al. (2010). Dabigatran versus enoxaparin for prevention of venous thromboembolism after hip or knee arthroplasty: a pooled analysis of three trials. Thromb. Res. 126, 175-182.

Fuji, T., Fuijita, S., Ujihira, T., and Sato, T. (2010). Dabigatran etexilate prevents venous thromboembolism after total knee arthroplasty in Japanese patients with a safety profile comparable to placebo. J. Arthroplasty 25, 1267-1274.

Furugohri, T., Isobe, K., Honda, Y., Kamisato-Matsumoto, C. Sugiyama, N., Nagahara, T., et al. (2008). DU-176b, a potent and orally active factor $\mathrm{Xa}$ inhibitor: in vitro and in vivo pharmacological profiles. J. Thromb. Haemost. 6, 1542-1549.

Garnock-Jones, K. P. (2011). Dabigatran etexilate: a review of its use in the prevention of stroke and systemic embolism in patients with atrial fibrillation. Am. J. Cardiovasc. Drugs 11, 57-72.

Ginsberg, J. S., Davidson, B. L., Comp, P. C., Francis, C. W., Friedman, R. J., Huo, M. H., et al. (2009). Oral thrombin inhibitor dabigatran etexilate vs. North American enoxaparin regimen for prevention of venous thromboembolism after knee arthroplasty surgery. J. Arthroplasty 24, 1-9.

Granger, C. B., Alexander, J. H., McMurray, J. J., Lopes, R. D., Hylek, E. M., Hanna, M., et al. (2011). Apixaban versus warfarin in patients with atrial fibrillation. N. Engl. J. Med. 365, 981-992.

Griffin, J. H. (1995). Blood coagulation. The thrombin paradox. Nature 378 , 337-338.

Gustafsson, D., Bylund, R., Antonsson, T., Nilsson, I., Nystroem, J.-E., Eriksson, U., et al. (2004). Case history: a new oral anticoagulant: the 50-year challenge. Nat. Rev. Drug Discov. 3, 649-659.

Hankey, G. J., and Eikelboom, J. W. (2011). Dabigatran etexilate: a new oral thrombin inhibitor. Circulation 123, 1436-1450.

Härtter, S., Koenen-Bergmann, M., Sharma, A., Nehmiz, G., Lemke, U. Timmer, W., et al. (2012). Decrease in the oral bioavailability of dabigatran etexilate after co-medication with rifampicin. Br. J. Clin. Pharmacol. 74, 490-500. 
Hauel, N. H., Nar, H., Priepke, H., Ries, U., Stassen, J. M., and Wienen, W. (2002). Structure-based design of novel potent nonpeptide thrombin inhibitors. J. Med. Chem. 45, 1757-1766.

Himmelsbach, F., Austel, V., Guth, B., Linz, G., Mueller, T. H., Pieper, H., et al. (1995). Design of potent nonpeptidic fibrinogen receptor antagonists. Eur. J. Med. Chem. 30, 243s254s.

Hirsh, J., Bauer, K. A., Donati, M. B., Gould, M., Samama, M. M., and Weitz, J. I. (2008). Parenteral anticoagulants: American college of chest physicians evidence-based clinical practice guidelines (8th edition). Chest 133, 141S-159S.

Hirsh, J., Dalen, J. E., Anderson, D. R., Poller, L., Bussey, H., Ansell, J., et al. (1998). Oral anticoagulants. Mechanism of action, clinical effectiveness, and optimal therapeutic range. Chest 114, 445S-469S.

Hoffman, A., and Galle, P. R. (2013). Gastrointestinal disorders and dabigatran. Scand. J. Gastroenterol. 48, 9-16.

Huisman, M. V., Lip, G. Y., Diener, H. C., Brueckmann, M., van Ryn, J., and Clemens, A. (2012). Dabigatran etexilate for stroke prevention in patients with atrial fibrillation: resolving uncertainties in routine practice. Thromb. Haemost. 107, 838-847.

Iodice, S., Gandini, S., Lohr, M., Lowenfels, A. B., and Maisonneuve, P. (2008). Venous thromboembolic events and organ-specific occult cancers: a review and meta-analysis. J. Thromb. Haemost. 6, 781-788.

Kadoglou, N. P., Moustardas, P., Katsimpoulas, M., Kapelouzou, A., Kostomitsopoulos, N., Schafer, K., et al. (2012). The beneficial effects of a direct thrombin inhibitor, dabigatran etexilate, on the development and stability of atherosclerotic lesions in apolipoprotein E-deficient mice: dabigatran etexilate and atherosclerosis. Cardiovasc. Drugs Ther. 26, 367-374

Lane, D. A., Philippou, H., and Huntington, J. A. (2005). Directing thrombin. Blood 106, 2605-2612.

Lee, I. O., Kratz, M. T., Schirmer, S. H., Baumhakel, M., and Bohm, M. (2012). The effects of direct thrombin inhibition with dabigatran on plaque formation and endothelial function in apolipoprotein Edeficient mice. J. Pharmacol. Exp. Ther. 343, 253-257.

Levi, M., van der Poll, T., and Schultz, M. (2012). New insights into pathways that determine the link between infection and thrombosis. Neth. J. Med. 70, 114-120.

Maegdefessel, L., Linde, T., Krapiec, F., Hamilton, K., Steinseifer, U., van Ryn, J., et al. (2010). In vitro comparison of dabigatran, unfractionated heparin, and low-molecular-weight heparin in preventing thrombus formation on mechanical heart valves. Thromb. Res. 126, e196-e200.

Mann, K. G. (2005). The challenge of regulating anticoagulant drugs: focus on warfarin. Am. Heart J. 149, S36-S42.

McAdow, M., Kim, H. K., Dedent, A. C., Hendrickx, A. P., Schneewind, O., and Missiakas, D. M. (2011). Preventing Staphylococcus aureus sepsis through the inhibition of its agglutination in blood. PLoS Pathog. 7:e1002307. doi:10.1371/journal.ppat.1002307

McKellar, S. H., Abel, S., Camp, C. L., Suri, R. M., Ereth, M. H., and Schaff, H. V. (2011). Effectiveness of dabigatran etexilate for thromboprophylaxis of mechanical heart valves. J. Thorac. Cardiovasc. Surg. 141, 1410-1416.

Oldgren, J., Budaj, A., Granger, C. B., Khder, Y., Roberts, J., Siegbahn, A., et al. (2011). Dabigatran vs. placebo in patients with acute coronary syndrome on dual antiplatelet therapy: a randomised, double blind, phase II trial. Eur. Heart J. 32, 2781-2789.

Palumbo, J. S., and Degen, J. L. (2000). Hemostatic factors in tumor biology. J. Pediatr. Hematol. Oncol. 22, 281-287.

Patel, M. R., Mahaffey, K. W., Garg, J., Pan, G., Singer, D. E., Hacke, W., et al. (2011). Rivaroxaban versus warfarin in nonvalvular atrial fibrillation. N. Engl. J. Med. 365, 883-891.

Perzborn, E., Roehrig, S., Straub, A., Kubitza, D., and Misselwitz, F. (2011). The discovery and development of rivaroxaban, an oral, direct factor Xa inhibitor. Nat. Rev. Drug Discov. 10, 61-75.

Pinto, D. J. P., Orwat, M. J., Koch, S., Rossi, K. A., Alexander, R. S., Smallwood, A., et al. (2007). Discovery of 1-(4-methoxyphenyl)7-oxo-6-(4-(2-oxopiperidin-1yl)phenyl)-4,5,6,7-tetrahydro1H-pyrazolo[3,4-c]pyridine3-carboxamide (apixaban, BMS-562247), a highly potent, selective, efficacious, and orally bioavailable inhibitor of blood coagulation factor Xa. J. Med. Chem. 50, 5339-5356.
Pinto, D. J. P., Smallheer, J. M., Cheney, D. L., Knabb, R. M., and Wexler, R. R. (2010). Factor Xa inhibitors: next-generation antithrombotic agents. J. Med. Chem. 53 6243-6274.

Preusch, M. R., Wijelath, E. S., Cabbage, S., Ieronimakis, N., Callegari, A., Bea, F., et al. (2010). Dabigatran etexilate a new oral thrombin inhibitor retards the initiation and progression of atherosclerotic lesions and inhibits the expression of oncostatin $\mathrm{M}$ in apolipoprotein $\mathrm{E}$ deficient mice. Arterioscler. Thromb. Vasc. Biol. 30, e185. [Abstract].

Schomburg, J. L., Medina, E. M., Lahti, M. T., and Bianco, R. W. (2012). Dabigatran versus warfarin after mechanical mitral valve replacement in the swine model. J. Invest. Surg. 25 , 150-155.

Schulman, S., Baanstra, D., Eriksson, H. Goldhaber, S., Kakkar, A., Kearon, C., et al. (2011a). Dabigatran versus placebo for extended maintenance therapy of venous thromboembolism. J. Thromb. Haemost. 9(Suppl. 2), 22.

Schulman, S., Eriksson, H., Goldhaber, S. Z., Kakkar, A. K. L., Kearon, C., Kvamme, A. M., et al. (2011b). Dabigatran or warfarin for extended maintenance therapy of venous thromboembolism. J. Thromb. Haemost. 9(Suppl. 2), 731-732.

Schulman, S., Kearon, C., Kakkar, A. K., Mismetti, P., Schellong, S., Eriksson, H., et al. (2009). Dabigatran versus warfarin in the treatment of acute venous thromboembolism. N. Engl. J. Med. 361, 2342-2352.

Stangier, J., and Clemens, A. (2009). Pharmacology, pharmacokinetics, and pharmacodynamics of dabigatran etexilate, an oral direct thrombin inhibitor. Clin. Appl. Thromb. Hemost. 15(Suppl. 1), 9S-16S.

Tan, A. Y., and Zimetbaum, P. (2011). Atrial fibrillation and atrial fibrosis. J. Cardiovasc. Pharmacol. 57, 625-629.

Van de Werf, F., Brueckmann, M., Connolly, S. J., Friedman, J., Granger, C. B., Härtter, S., et al. (2012). A comparison of dabigatran etexilate with warfarin in patients with mechanical heart valves: THE randomized, phase II study to evaluate the safety and pharmacokinetics of oral dabigatran etexilate in patients after heart valve replacement (RE-ALIGN). Am. Heart J. 163 931-937. van der Poll, T., de Boer, J. D., and Levi, M. (2011). The effect of inflammation on coagulation and vice versa. Curr. Opin. Infect. Dis. 24, 273-278.

van Ryn, J., Dietze, T., Kuritsch, I., Kink-Eiband, M., and Wienen, W. (2009). Effect of the direct thrombin inhibitor, dabigatran, on arterial thrombosis when given in combination with aspirin (ASA) in a cyclic flow model in anesthetised pigs. $J$. Thromb. Haemost. 7(Suppl. 2), 435. [Abstract].

van Ryn, J., Hauel, N., Waldmann, L. and Wienen, W. (2008). Dabigatran inhibits both clot-bound and fluidphase thrombin in vitro: comparison to heparin and hirudin. Arterioscler. Thromb. Vasc. Biol. 28, e136e137.

van Ryn, J., Stangier, J., Haertter, S. Liesenfeld, K. H., Wienen, W., Feuring, M., et al. (2010). Dabigatran etexilate - novel, reversible, oral direct thrombin inhibitor: interpretation of coagulation assays and reversal of anticoagulant activity. Thromb. Haemost. 103, 1116-1127.

Vanassche, T., Kauskot, A., Verhaegen, J., Peetermans, W. E., van Ryn, J., Schneewind, O., et al (2012). Fibrin formation by staphylothrombin facilitates Staphylococcus aureus-induced platelet aggregation. Thromb. Haemost. 107, 1107-1121.

Vanassche, T., Verhaegen, J., Peetermans, W. E., Hoylaerts, M. F., and Verhamme, P. (2010). Dabigatran inhibits Staphylococcus aureus coagulase activity. J. Clin. Microbiol. 48, 4248-4250.

Vanassche, T., Verhaegen, J., Peetermans, W. E., Van Ryn, J., Cheng, A., Schneewind, O., et al. (2011). Inhibition of staphylothrombin by dabigatran reduces Staphylococcus aureus virulence. J. Thromb. Haemost. 9, 2436-2446.

Warkentin, T. E., Greinacher, A., and Koster, A. (2008). Bivalirudin. Thromb. Haemost. 99, 830-839.

Wienen, W., Stassen, J.-M., Priepke, H., Ries, U.-J., and Hauel, N. (2007a). In-vitro profile and ex-vivo anticoagulant activity of the direct thrombin inhibitor dabigatran and its orally active prodrug, dabigatran etexilate. Thromb. Haemost. 98 , 155-162.

Wienen, W., Stassen, J.-M., Priepke, H., Ries, U.-J., and Hauel, N. (2007b). Effects of the direct thrombin inhibitor dabigatran 
and its orally active prodrug, dabigatran etexilate, on thrombus formation and bleeding time in rats. Thromb. Haemost. 98, 333-338.

Wienen, W., Stassen, J.-M., Priepke, H., Ries, U.-J., and Hauel, N. $(2007 \mathrm{c})$. Antithrombotic and anticoagulant effects of the direct thrombin inhibitor dabigatran, and its oral prodrug, dabigatran etexilate, in a rabbit model of venous thrombosis. J. Thromb. Haemost. 5, 1237-1242.
Yeh, R. W., and Jang, I.-K. (2006). Argatroban: update. Am. Heart J. 151, 1131-1138.

Zhang, P., Huang, W., Wang, L., Bao, L., Jia, Z. J., Bauer, S. M., et al. (2009). Discovery of betrixaban (PRT054021), N(5-chloropyridin-2-yl)-2-(4-(N,Ndimethylcarbamimidoyl)benzamido) 5-methoxybenzamide, a highly potent, selective, and orally efficacious factor $\mathrm{Xa}$ inhibitor. Bioorg. Med. Chem. Lett. 19 2179-2185.
Conflict of Interest Statement: All authors are employees of Boehringer Ingelheim $\mathrm{GmbH}$.

Received: 27 November 2012; paper pending published: 23 December 2012; accepted: 23 January 2013; published online: 12 February 2013.

Citation: van Ryn J, Goss A, Hauel $N$, Wienen $W$, Priepke $H, N a r H$ and Clemens A (2013) The discovery of dabigatran etexilate. Front. Pharmacol. 4:12. doi: 10.3389/fphar.2013.00012
This article was submitted to Frontier in Cardiovascular and Smooth Muscle Pharmacology, a specialty of Frontiers in Pharmacology.

Copyright (C) 2013 van Ryn, Goss, Hauel, Wienen, Priepke, Nar and Clemens. This is an open-access article distributed under the terms of the Creative Commons Attribution License, which permits use, distribution and reproduction in other forums, provided the original authors and source are credited and subject to any copyright notices concerning any third-party graphics etc. 